\title{
Interactivity on Swedish newspaper websites: What kind, how much and why?
}

Convergence: The International Journal of Research into New Media Technologies 18(2) 195-213

(C) The Author(s) 2012

Reprints and permission: sagepub.co.uk/journalsPermissions.nav DOI: 10.1 |77/|3548565||430|84 con.sagepub.com

@SAGE

\author{
Anders Olof Larsson \\ Uppsala University, Sweden
}

\begin{abstract}
This article examines what kind of interactive features are available on the websites of Swedish newspapers, and what factors seem to influence the utilization of those features. Using Chung's typology of interactive features, we can discern four types: human (features that facilitate interpersonal communication), human-medium (allowing users to express their personal opinions), medium (allowing users choice options in experiencing news stories) and medium-human (allowing users to customize news to their liking) interactive features. Factors believed to have influence over interactive features are tested using statistical analysis. Even though different factors tend to influence different types of interactivity, results indicate that the most interactive newspaper websites belong to large, national newspapers with younger web staff.
\end{abstract}

\section{Keywords}

citizen journalism, interactivity, journalism, online newspapers, Sweden

\section{Introduction}

Following the rapid spread of internet usage during the mid-1990s, established media worldwide began expressing fears regarding the consequences of the expansion of the new medium. Among other things, it was suggested that print media especially would not fare well in the new digital era (Thurman and Myllylahti, 2009). Beliefs were also aired that the interactive potential of the internet would come to change, or at least influence, the practice of journalism, moving it from a one- to a two-way communication process (Chung, 2007, 2008; Hujanen and Pietikainen, 2004), leveling the playing field between journalist and reader, sender and receiver. Today, many media outlets are indeed experiencing economic difficulties, while at the same time, many are investing resources into providing informative, interactive and varied websites for their audiences. This 
article will study the websites of Swedish newspapers; more specifically how these websites make use of what is often described as the defining character of the internet medium: interactivity (Downes and McMillan, 2000; Gillmor, 2004; Kiousis, 2002).

The need to investigate how newspaper websites make use of interactive features in countries other than the USA has been acknowledged by previous research (Chung, 2007: 577; Mitchelstein and Boczkowski, 2009). In addition, the Swedish media market might be especially interesting to study in this regard, mainly because of relatively high overall newspaper readership, as well as widespread internet penetration and usage (Carlsson and Facht, 2007; Facht, 2008). Although much work has been done looking into what types of interactive features are offered on newspaper websites, this work has mainly been descriptive, and the question of why such features are employed has not been clearly addressed (Boczkowski, 2002: 277; Chung, 2007: 43-44). With this in mind, the aim of this study is to examine what kind of interactive features are available on the websites of Swedish newspapers, and what factors seem to influence the utilization of those features.

This article is organized as follows. First, earlier research on internet newspapers and the study of interactivity on newspaper websites are discussed. Following this, factors that are often thought to influence website features such as interactivity are identified. After the subsequent methodology section, the results of the study are presented and discussed. The article finishes with a description of the limitations of the study and provides a few suggestions for future research projects.

\section{Background}

The body of research on online newspapers and online journalism offers a multitude of research areas and approaches (see Mitchelstein and Boczkowski, 2009: for a review). Likewise, many studies on online interactivity have been published, identifying a number of different views on the topic. Although journalism has been described as 'always influenced by technology' (Pavlik, 2000: 229), the influences provided by recent technological developments seem to have taken some time to gain ground in the journalistic work environment. The next section offers a research review on interactivity in the journalistic context. Since interactivity has been conceptualized in a variety of ways as well as used in many different scientific disciplines, the section after that will provide an overview of some of the ways that this concept has been used within the social sciences.

\section{Newspapers on the internet - cautious traditionalists}

From early on, it seems that the established media have indeed taken on the roles of 'cautious traditionalists' (Chung, 2007: 53) when dealing with the internet medium. In one of the first studies on online newspaper appropriation of interactive features, Newhagen and Cordes (1995) showed how media professionals had difficulty adapting to the underlying potential for two-way communication that characterizes the new medium. Although some journalists expressed an interest in the more direct way of communicating with readers made possible by the digital development (Chung, 2007), these ambitions seemed to be thwarted by what might be described as 'conservative' or 'traditional' journalistic schooling and thinking (Domingo, 2008; Gillmor, 2004), as well as the professed merits and non-merits of online publishing. For example, in his survey of journalists at The New York Times, Schultz (2000) found that of those questioned, the majority did not take an interest in the Times' own forums. The use of interactive features, such as user discussion forums, is often seen as increasing the workload for journalists because of the perceived need for 
fact- and language-checking reader contributions (Chung, 2007; Thurman, 2008). The hesitancy described earlier could perhaps also be understood as a result of the business-like, increasingly commercial, non-egalitarian character of newspapers (Martin and Hansen, 1998). Similar studies seem to produce comparable results to the ones discussed here, indicating that journalists and editors-in-chief alike are somewhat bewildered by the new medium, seeing threats as well as possibilities (Boczkowski, 2004; Quinn and Trench, 2002). The lack of interaction has led some researchers to conclude that most newspapers use their online versions as mirrors of their printed counterparts, where content from the latter is simply 'lifted' into the former without substantial augmentation. This transferring of content from print to web is often referred to as 'shovelware' journalism, indicating that little or no adaptation to the new medium has been undertaken (Chyi and Sylvie, 1998; Riley et al., 1998; Schultz, 1999). However, Boczkowski (2004) points out that one should not underestimate the cumulative transformation effect that online newspapers seem to be undergoing - perhaps as a result of increasing online competition between newspapers, online durability or increasingly aggressive other online actors, recent studies have found increased levels of interactivity on various newspaper websites. Greer and Mensing (2006) reported an increase of interactive features, albeit minimal, in their longitudinal study of online US newspapers, and similar results have been reported by other scholars (Chung, 2004; Mitchelstein and Boczkowski, 2009).

In a Scandinavian context, newspapers seem to be slowly embracing the concept of interactivity (Engebretsen, 2006; Karlsson, 2006). Indeed, media organizations in Sweden as well as elsewhere appear increasingly positive towards augmenting their press title websites with interactive functionalities (Frisk, 2008). Rightfully so, it would seem - an audience-centered study conducted in the USA indicates that more interactive possibilities on newspapers' websites result in a sense of belonging or commitment towards the specific web page (Shyam Sundar, 2000). Outing (2001), quoted in Deuze (2003), comments that this commitment seems to appear even if the individual user does not choose to partake in using the different interactive features available on the site. Other researchers have found that more interactive features on websites tend to result in positive attitudes towards the site itself (McMillan, 2000a; McMillan et al., 2003). Although these positive effects of interactivity have been contested (as pointed out by McMillan, 2002b), researchers from a variety of disciplines seem to agree that a variety of opportunities for interactivity will lead to an increase in web-surfer satisfaction as well as surfer behavior such as repeat visits, purchasing from the site (where applicable) as well as referring others to it (Aikat, 1998; Kiernan and Levy, 1999; $\mathrm{Wu}, 1999)$. All together, research seems to indicate that a website rich with interactive features will lead to more, as well as more active, visitors, as well as a sense of commitment or belonging from those visitors.

\section{Different views on interactivity}

In 1998, Jensen stated that the concept of interactivity is hard to describe explicitly because of its widespread usage not only in academia, but also in society at large. He argued that our 'culture has lived out what we might call the interactive turn', where interactivity permeates all of society, and therefore is 'watered down' as an academic and scientific concept (1998: 186). Schultz mirrors these opinions when he refers to the term as 'inflated' and as a 'dull buzzword' (2000: 205). Recently, Domingo (2008: 686) argued that the concept of interactivity is 'a bit too elastic', pointing at 'the wide range of options referred to under the label of interactivity'. Indeed, interactivity has been 'often mentioned but seldom operationalized' (McMillan and Hwang, 2002: 29). Even though efforts have been made towards presenting a clearer definition, more than a decade 
after Jensen's article uncertainty still remains regarding what interactivity is and how it might be understood academically (see also Bucy, 2004; Koolstra and Bos, 2009).

Judging from the literature available, we can distinguish three main views on interactivity: functional, perceived and process. Rather than a typology of interactivity, these three views represent different approaches that scholars have chosen when pursuing research on interactivity.

Studies adopting a functional view often employ content analysis to find 'specific features that can be identified and categorized as interactive' (McMillan, 2002a: 165) and mostly define levels of interactivity as the presence or absence of specific features (Song and Zinkhan, 2008: 100). Sundar's related claim that 'Interactivity is a message (or medium) attribute, not a user attribute' (2004: 386) has not gone unchallenged, however. To illustrate, Gerpott and Wanke (2004) opted for the functional view in their study of interactive features of German press titles on the web, stating that this view 'avoids perceptual distortions included in user-web site interactivity ratings caused by idiosyncrasies of visitors' (Gerpott and Wanke, 2004: 245). However, as McMillan (2000a) points out, interactivity might well be located 'in the eye of the beholder', rather than being a purely functional feature. Simply adding more interactive features does not automatically increase the levels of perceived interactivity (Song and Zinkhan, 2008: 109), that is, how visitors of websites tend to perceive various interactive features (Downes and McMillan, 2000; Kiousis, 2002; McMillan, 2000a; Newhagen and Cordes, 1995). The apparently much less employed process view involves focusing on discourse and the reciprocity between the participants in communicative contexts. For example, Rafaeli and Sudweeks (1997) define interactivity as the 'relatedness' of sequential messages in a specific communicative context. Similar definitions and studies have followed (e.g., Kiousis, 2002; Koolstra and Bos, 2009).

Most research regarding interactive features of online newspapers has been descriptive and has not attempted to explain why certain publications employ interactive features to higher or lower degrees (Chung, 2007: 43-44). Trying to move beyond this 'mere counting' of different interactive features available on these websites (as suggested by Boczkowski, 2002: 277), this article will employ a functional view of interactivity and will also attempt to analyze what factors seem to influence the employment of interactive features. As made clear from the foregoing discussion, the choice of a functional view is not without its limitations. For one thing, by focusing only on the website itself, a functional approach will inevitably exclude the site visitors from scrutiny. However, the focus of this study is on the websites of Swedish newspapers and not on the visitors of these sites. Although it seems clear that the perceived or the process view respectively could provide interesting insights regarding these matters, applying and augmenting the functional view in the way proposed earlier should provide the research community with important insights as to why newspaper websites vary when it comes to their utilization of interactive features.

\section{Chung's typology of interactive features}

Regardless of whether one chooses to study interactivity from the functional, perception or process view, the literature identifies several different ways to synthesize different types of interactive features often found on websites. Two such types that frequently appear in the research available are human and medium interactivity (e.g., Bucy, 2004; Chung, 2008; McMillan, 2002b). Human interactivity refers to diverse facilitations of user-to-user-interaction, such as chat rooms and message boards. This dimension of interactivity draws on what is often labeled a sociological definition of the concept (Downes and McMillan, 2000), and largely builds on the ideal of face-to-face 
interaction as the default or standard form of interactivity (e.g., Walther and Burgoon, 1992) and how the inherent 'conversational ideal' is used to understand and evaluate the different kinds of interactivity available on websites. Medium interactivity refers to the various ways that visitors to websites are allowed different choice options when browsing them. This type of interactivity regularly includes descriptions of such basic features of websites as different navigational possibilities for the site visitor or ways in which the users are allowed to interact with the content on the site. In the context of news websites, medium interactivity features might include video streams and interactive news graphics.

In a recent article, Chung (2008) opted for a perceived view of interactivity when studying patterns of online newspaper readers' uses of interactive features. Providing empirical data, Chung showed that her respondents not only identified human and medium interactive features, but also combinations of the two. Accordingly, a human-medium interactive feature 'allows users to express their opinion' (Chung, 2008: 666) within the confines of the site. Utilizing these kinds of features will allow users to contribute to the site themselves by uploading and annotating their own texts and pictures. In other words, newspaper websites rich with human-medium interactivity are in some ways 'engaging users as content co-producers' (Boczkowski, 2002: 278). Common functions include 'submit stories,' 'submit photos,' 'submit news tips,' and letters-to-the-editor features. Features grouped under the medium-human label allow for user customization of site content. This follows what Deuze (2003: 214) has called an adaptive ideal, giving the users control, allowing them to choose what kind of news to consume and when to consume it. Common functions include customized topics, headlines and so on as well as various search and alerts features.

This article will employ the suggested typology in order to classify the interactive features found on Swedish newspaper websites. Three main reasons for employing this typology can be discerned: first, it is empirically grounded; second, it was developed specifically with newspaper websites in mind; third, it goes beyond the distinction between human and medium interactivity and provides the research community with a more diverse way of looking at the concept at hand. The four-part typology of interactivity was further elaborated in Chung and Nah's recent article (2009), and its main features are summarized in Table 1.

While the typology introduced here provides a suitable starting point for approaching different types of interactivity in the online newspaper context, we must also attempt to asses what factors appear to have influence on the utilization of the different types. The next section introduces a number of such influences, based on the findings of previous research.

\section{Influences for utilizing interactive features}

Since the websites studied in this article are all subsidiaries of print newspapers, it seems reasonable to view interactivity as a form of newspaper content. Looking at earlier studies, it can be concluded from the extensive body of research available that newspaper content is influenced by several factors, both internal and external to the media company itself. Building on a literature review of earlier research, this article will employ the following factors as independent variables: newspaper size, media ownership, region and competition within region, length of web presence and number and age of staff. These factors and the motivations for including them as independent variables are described in detail in the following paragraphs. 


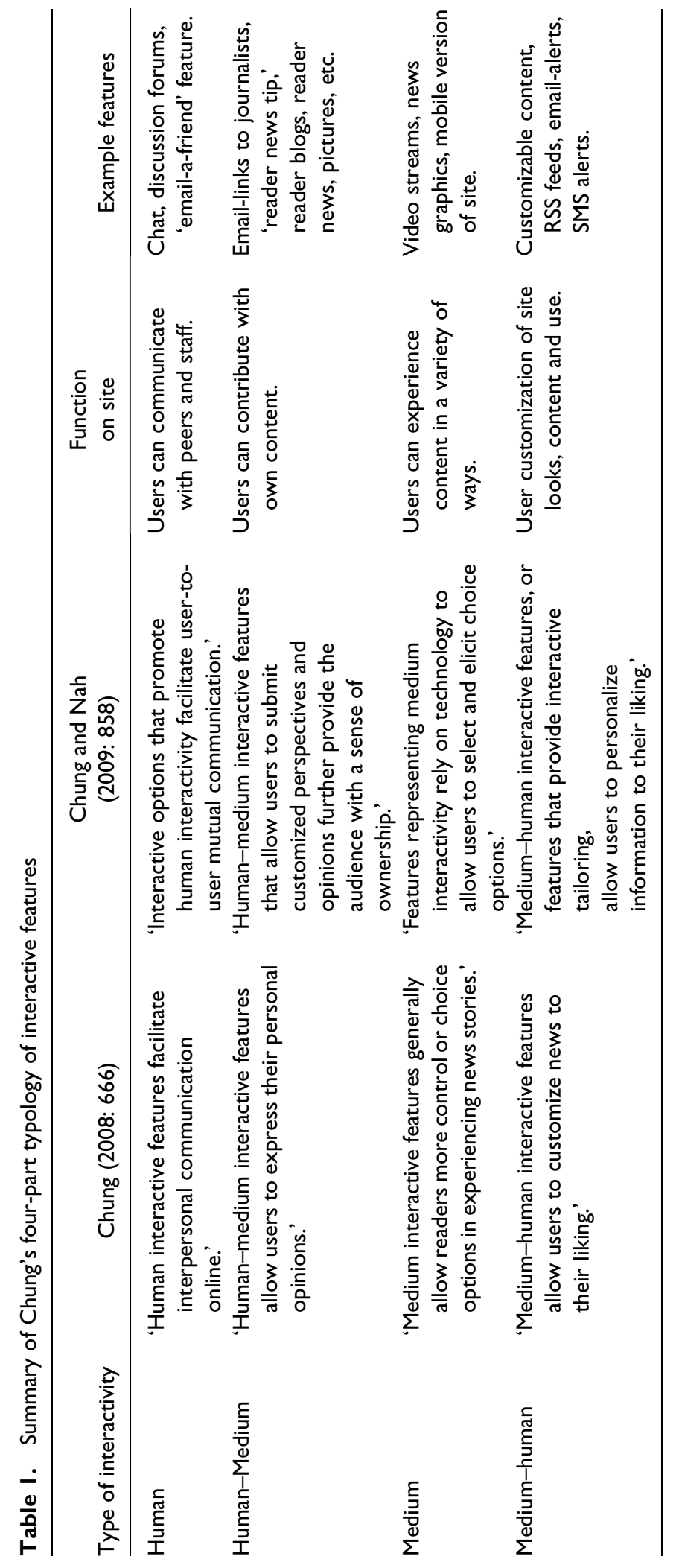




\section{Newspaper size}

When it comes to the characteristics of newspaper content, many studies indicate that factors regarding size matter. Nerone and Barnhurst (2001) studied the websites of US newspapers, finding that larger newspapers offered more interactive features on their websites than their smaller equivalences. Even though Shultz's (1999) study largely ignored other types of interactivity than human, his results indicate that the size (operationalized as printed newspaper circulation) of the newspaper could be a good indicator of online interactive features. Similarly, Gubman and Greer (1997) found that the circulation of the associated print newspaper was a reliable predictor of website sophistication. Performing longitudinal studies of newspaper websites from 1997 to 2003, Greer and Mensing reported that 'whereas medium and large newspapers now have equally sophisticated sites, the small newspapers lag behind in every measure' (2006: 29). This view of 'strength-in-numbers' is contrasted by studies that show somewhat opposite results. In their study of the websites of 300 US TV-stations, Chan-Olmsted and Park (2000) found that market size was the least relevant predictor of site contents. Similar results were reported by Lin and Jeffries (2001) in their study of the websites of US newspapers, radio- and television stations. In conclusion, Massey (2000) found that although newspaper circulation correlated positively with the degree of customization (here labeled as medium-human interactivity) available to users, it did not significantly predict other aspects of interactivity. Following Zeng and Li (2006), it nevertheless seems plausible that larger media organizations would offer more interactive features on their websites than smaller ones. As suggested by the studies mentioned earlier, circulation of the parent newspapers will be used as a measure of newspaper size.

\section{Media ownership}

Since the 1980s, the international media market has been increasingly characterized by ownership concentration (Picard, 1989), often creating media ownership chains. Characteristics of media owners, particularly economic ones, are often regarded as having influences on media content and journalistic professionalism (e.g., Beam, 1993). For online conditions, results indicate that media owner characteristics could be good predictors of website contents (Chan-Olmsted and Park, 2000), as well as studies stating the opposite (Adams, 2007; Schultz, 1999). Nevertheless, it seems relevant to include a variable measuring the size of the media owner. In order to assess the economic strength of owners, the net economic result of newspaper owners will be included in the analysis.

\section{Region and competition within region}

It seems reasonable to assume that 'big, national news sites with more money, broader coverage scope ... would be in a better position to set up a highly interactive news website than local newspapers' (Zeng and Li, 2006: 144). For Swedish conditions, at least some of the national newspapers seem to give weight to this statement (Hadenius and Weibull, 1999) However, mixed research results are found when it comes to the influence that region of operation appears to have, both supporting (Peng et al., 1999) and rejecting (Dibean and Garrison, 2001) it. In their 2006 study, Zeng and $\mathrm{Li}$ (2006) found that the websites of national newspapers offered more of what the authors called content interactivity (here labeled medium and medium-human interactivity) than 
their local counterparts, but non-significant results when it came to differences concerning communicative interactivity (here human and human-medium interactivity). In order to gauge any differences, the study will include data on whether newspapers operate on a local or national level.

There might also be an effect from competition between newspapers operating in the same region. Competition among newspapers has been described as having an enhancing effect on the quality of journalistic output (Lacy, 1989) - a claim that seems plausible also for online web versions of newspapers. For example, Chyi and Sylvie (1998) suggested that development of specific internet-related features (such as interactivity) might be of importance to newspaper sites engaged in regional competition. However, in an early study of 62 television websites, Kiernan and Levy (1999) found little relation between website characteristics and station competition. In order to assess any variation stemming from competition, a variable measuring the number of competitors within each newspaper's region of publication will be included.

\section{Length of web presence}

As discussed earlier, there might be a cumulative effect of online longevity on the contents of newspaper websites. Although she stresses that the development of interactive features on these types of sites is scarce, Chung claims that 'positive accounts of news publications' implementation of interactivity with increasing sophistication in form and content over time exist' (2008: 662), a position partly supported by Schultz (2000). As pointed out by Zeng and Li, the internet is a relatively new medium that has gone through substantial changes regarding structure as well as content during its short lifespan (Zeng and $\mathrm{Li}, 2006$ : 144). Longer experience in operating and maintaining professional websites might result in more refined content and advanced features. Consequently, a variable measuring the length of online presence for each newspaper's website will be included.

\section{Number and age of staff}

The number of website staff might be a valid predictor of site sophistication (Arant and Anderson, 2001). Indeed Chyi and Sylvie (1998: 5) state that 'maintaining interactive services can be extremely labor intensive'. In a study from the same year, Tankard and Ban (1998) found number of staff to be a significant predictor of certain aspects of internet publishing, although it did not correlate significantly with their measurement of interactivity. Conversely, Zeng and Li (2006) concluded that number of staff was one of the better predictors of interactivity on newspaper websites. These results might suggest that the influence of number of staff has grown more important over time.

Addressing the age factor, several studies have shown that younger generations are generally better versed in using interactive features than older people (e.g., Facht, 2008). Younger journalists also tend to be more educated than their older colleagues (Deuze and Dimoudi, 2002), which might have some effect in this regard. Additionally, in her study on the IT usage of Swedish journalists, Balsvik (2004) proposed that age differences should be considered in future studies. All together, these findings indicate that younger journalists will be more inclined towards using and utilizing interactive features on their respective newspaper websites. When it comes to factors relating to website staff, variables measuring the number and age of this staff will be included in the analysis. 


\section{Method}

A comprehensive list of Swedish newspapers was gathered from The Swedish Newspaper Publishers' Association (dagspress.se, n.d.). The population consisted of 143 websites. Sites that did not offer any journalistic content $(\mathrm{N}=35,25 \%)$ or that featured incomprehensible language $(\mathrm{N}=2,1 \%)$ were excluded. The final number of sites to be analyzed was $106(74 \%$ of the population. Data regarding newspaper size (operationalized as circulation of parent newspaper), media ownership (operationalized as net result of owner), region (operationalized as local or national region of operation) and competition within region (operationalized as total $\mathrm{N}$ of newspapers within each respective region) were gathered from three sources: The Swedish Newspaper Publishers' Association (dagspress.se, n.d.), a feature in the Swedish journalist's trade union paper (Frigyes, 2008) and http://allabolag.se/ (allebolag.se, n.d.), a website providing information regarding finances, ownership and so forth for Swedish enterprises. Data regarding length of web presence (operationalized as $\mathrm{N}$ of days the newspaper had had a website), number and age of staff (operationalized as $\mathrm{N}$ and mean age of web staff) was obtained by means of a small questionnaire sent to the webmasters of the included websites. After two reminders, answers were received from $65(61.3 \%)$ of the newspapers included in the study.

\section{Content analysis}

Content analysis has historically been used to study 'fixed' communication artifacts such as newspaper articles or television segments (Krippendorff, 2004). As shown by McMillan (2000b), the method can also be applied to the internet. This study employed Krippendorf's terminology of sampling, coding and context units to guide the analysis. Sampling units are defined as 'units that are distinguished for selective inclusion in an analysis' (Krippendorff, 2004: 98). This study chose a twofold view of sampling units. First, the start or home pages of the websites were analyzed. Weare and Lin suggest that 'this strategy works well for research questions that focus on generic dimensions of web content' such as interactive features, and further that 'given its attentiongrabbing and organizational roles, a home page is likely to contain many central elements of web design' (2000: 281). Any interactive feature presented and/or linked to from the home page was coded. Second, more 'news-specific' features of interactivity, such as user comments on news stories, were included. In order to find these features, the headlining news story from the start page of each site was analyzed. Interactive features were coded as present or non-present on the sites.

Coding units are 'units that are distinguished for separate description, recording or coding' (Krippendorff, 2004: 99-101). Coding units, or variables, were created using the four-part typology of interactivity presented earlier. This process was based on features identified in previous research as discussed earlier. All of the websites were also visited before the analysis in order to detect interactive features not identified in previous studies. In total, 34 coding units were recognized; 5 for human interactivity, 14 for human-medium, 10 for medium and 5 for medium-human (see Table 1 for examples of features). For each feature available on the websites, a score of 1 was recorded. Inspired by previous studies (e.g., Gerpott and Wanke, 2004; Massey, 2000), the variables for each type of interactivity were added and divided by their theoretical maximum value, thus creating four indices ranging from the minimal value of 0 to the maximum value of 1 . The same calculations were also performed for all interactivity variables in order to create an overall index, encompassing all types. 
As for context units, they are 'units of textual matter that set limits to be considered in the description of recording units' (Krippendorff, 2004: 101). Here, context units helped classify the coding units. For example, if a blog was found on one of the websites, it was determined if the blogger was affiliated with the site or a reader, if other readers were invited to start blogging on site and so on - in order to help classify the specific recording units.

\section{Coding procedure}

While online content is often described as ever changing (e.g., Koehler, 2002), focus here laid on the structural elements of newspaper websites, such as interactivity. Schultz (1999) states that the interactive features of newspaper websites are fairly constant, suggesting that although journalistic content might change, interactive features are more consistent. The coding procedure was finished within a week in January 2009, which could be considered a rapid time period (as recommended by McMillan, 2000b). To gauge reliability, a second coder was trained and recoded a random 20 per cent sample of the sites. Intercoder agreement ranged from .88, a score well above the common threshold of .80 (Krippendorff, 2004) to perfect agreement, all using Holsti's formula (1969). The overall figure of intercoder agreement was .96 .

\section{Results}

According to Sohn and Lee (2005), interactivity has often been described as a heterogeneous concept in theory, but treated as a homogenous one in empirical analysis, thereby failing to see the differences between the proposed underlying dimensions. Boczkowski comments on this as 'the lumping together of apples and oranges' (2002: 276-277) - a seemingly common practice of treating different forms of interactivity as the same when performing analysis. In order to determine any characteristics of or differences between the four types of interactivity used in this study, the results will be presented in a way that makes this distinguishable.

In order to test the influence of the factors identified earlier on the different types of interactivity (as well as on the total measure of interactivity), statistical analyses (multiple regression and mean comparison) were performed using the four types and the total as dependent variables respectively. Because these dependent variables did not meet the assumptions necessary for regression (i.e., the variables were not normally distributed), they were logit transformed in order to facilitate analysis. Results of the regression analysis can be found in Table 2 .

From the literature review presented earlier, we could conclude that larger newspapers would probably keep websites that featured higher levels of interactivity than smaller ones. The results in Table 2 show that the variable measuring newspaper size (circulation) does indeed emerge as a significant predictor for the total measure as well as for three of the specific measures (human, human-medium and medium-human). Although the size-related variable failed to significantly predict medium interactivity, the overall assessment is that size of the newspaper organization does indeed matter for levels of interactivity on their respective websites.

Previous research has also made the claim that financially strong media owners would have more resources available to invest in their newspapers, potentially resulting in higher degrees of interactivity on the websites of these newspapers. From Table 2 we can conclude that the net result of owner variable was not a significant predictor in any of the analyses performed. Owners, financially strong or not, appear to have limited influence over these websites - at least when it comes to interactivity. 
Table 2. Regression analyses of factors predicting interactivity

\begin{tabular}{lccccc}
\hline & Total & Human & Human-medium & Medium & Medium-human \\
\hline Circulation & $.33^{*}$ & $.40^{*}$ & $.32^{*}$ & .17 & $.36^{*}$ \\
Net result of owner & .12 & -.02 & .01 & -.04 & .08 \\
N of newspapers in region & -.16 & -.15 & -.23 & .08 & -.03 \\
Length of web presence & .07 & .17 & .02 & -.07 & .11 \\
Number of web staff & .25 & -.20 & .20 & $.50^{* * *}$ & $.28^{*}$ \\
Mean age of web staff & $-.30^{*}$ & -.02 & $-.3 I^{*}$ & .08 & -.10 \\
& $\mathrm{R}^{2}=.42 \mathrm{Adj}$. & $\mathrm{R}^{2}=.21$ Adj. & $\mathrm{R}^{2}=.32 \mathrm{Adj}$. & $\mathrm{R}^{2}=.40 \mathrm{Adj}$. & $\mathrm{R}^{2}=.41$ Adj. \\
& $\mathrm{R}^{2}=.34$ & $\mathrm{R}^{2}=.11$ & $\mathrm{R}^{2}=.23$ & $\mathrm{R}^{2}=.31$ & $\mathrm{R}^{2}=.33$ \\
\hline
\end{tabular}

Standardized Beta values presented, $*_{\mathrm{p}}<.0 \mathrm{I}, *_{\mathrm{p}}<.05$

Table 3. Mean comparisons of standardized interactivity scores

\begin{tabular}{lccccc}
\hline & Total & Human & Human-medium & Medium & Medium-human \\
\hline National newspaper & $.49(.22)$ & $.40(.30)$ & $.49(.19)$ & $.54(.28)$ & $.51(.25)$ \\
Local newspaper & $.34(.17)$ & $.34(.24)$ & $.37(.16)$ & $.29(.23)$ & $.32(.16)$ \\
Overall mean & $.35(.17)$ & $.35(.24)$ & $.38(.16)$ & $.31(.24)$ & $.34(.17)$ \\
& eta $^{2}=.05^{*}$ & eta $^{2}=.04$ & eta $^{2}=.03$ & eta $^{2}=.07 * *$ & eta $^{2}=.08^{* *}$ \\
\hline
\end{tabular}

$*_{\mathrm{p}}<.01, *_{\mathrm{p}}<.05$, Standard deviations in parenthesis

As discussed earlier, the websites of nationwide newspapers might be expected to offer more interactive features than the websites of their local counterparts. Table 3 shows the results of five mean comparison tests, measuring the differences in means of different interactivity scores between national and local newspapers.

From Table 3 we can tell that even though the mean differences of human and human-medium interactivity between national and regional newspapers were not significantly different, differences can be found when it comes to total interactivity (.49 and .34 respectively), as well as for medium (.54 and .29 respectively) and medium-human interactive features (.51 and .32 respectively). In general, the results indicate that national newspapers tend to offer more interactive features on their websites than local newspapers.

As previous research provided mixed results regarding the effects of competition on newspaper website performance, a variable assessing competition within each newspapers region ( $N$ of newspapers within region) was included in the analysis. As shown in Table 2 , this variable did not manage to significantly predict any of the four types of interactive features, nor did it predict the total amount of interactivity. In the Swedish context, competition between newspapers does not appear to have an effect on how online newspapers perform regarding utilization of interactive features.

Scholars have suggested that there might be a cumulative effect of longevity when it comes to the working routines of online newspapers. However, the length of web presence variable did not emerge as a significant predictor for any of the five measures under scrutiny here. When it comes to use of interactive features, online longevity does not seem to be an important factor in the Swedish media environment.

Maintaining a highly interactive website is frequently described as very labor intensive. Indeed, previous research has suggested that the number of website staff would have a positive effect on 
the availability of interactive features available on the various websites. From the regression analyses in Table 2, we can tell that even though the number of web staff variable significantly predicts levels of medium and medium-human interactivity, it fails to predict human, humanmedium or the total amount of interactivity. Thus, the number of employees working with the website apparently has some effect on the utilization of interactive features.

Previous research has suggested that employment of younger staff members would have positive effects on the availability of interactive features. The age variable included in the regression analyses, mean age of web staff, did indeed prove to be a significant predictor of total and humanmedium interactivity as shown in Table 2 . However, it failed to significantly predict the other three types of interactivity (human, medium and medium-human). Nevertheless, from these results it would seem that hiring younger web staff has at least a partial effect when it comes to their potential influence on the websites with which they work.

In sum, it seems that the websites in the study that offer higher levels of total interactivity are those that belong to large, national newspapers with younger web staff. However, the foregoing analyses did identify some interesting discrepancies regarding the predictors of the four types of interactivity. These discrepancies, and the overall results of the study, will be discussed in the next section of the article.

\section{Discussion}

While the results of statistical analyses, like those featured in this article, can provide overarching views for different research phenomena, they need to be contextualized with regards to previous research and the specific research setting in order to prove truly meaningful. As such, this section discusses the results presented earlier in relation to previous research as well as in relation to online journalistic practices.

The first independent variable (circulation) dealt with the size of the parent newspaper for each website. Even though earlier studies have disputed the link between newspaper size and website contents (e.g., Chan-Olmsted and Park, 2000; Lin and Jeffres, 2001; Massey, 2000), the results presented here suggest that, at least in the Swedish context, online interactive practices are indeed related to the size of the supporting newspaper (as suggested by Nerone and Barnhurst, 2001; Schultz, 1999). Evidently, the claim by Greer and Mensing that 'small newspapers lag behind' (2006: 29) seems valid also in the Swedish online media environment, indicating that smaller newspapers might have trouble holding their own when it comes to offering their readers opportunities to interact and contribute to their online versions. While the circulation variable failed to significantly predict employment of medium interactive features, the number of staff variable emerged as the sole significant predictor for this type of interactivity. This suggests that medium interactivity features, such as video streams, news graphics and so on, require the allocation of specific web staff to work exclusively with augmenting and servicing the website in this regard.

Related to the size of the newspaper is the size of the owner organization. Concentration of media ownership is increasing in the Swedish newspaper market, and studies have shown that the size of the owner is a suitable predictor of newspaper performance (Beam, 1993) as well as website sophistication (Chan-Olmsted and Park, 2000). The results presented here suggest the opposite, mirroring the conclusions of other previous studies (Adams, 2007; Schultz, 1999). As such, the size of the 'parent' organizations appear to have little to do with the online performance of the individual newspapers. Perhaps the explanation for this lack of 'strength in numbers' can be found among the theorists of media concentration. These scholars argue that large media owners tend to 
streamline content and focus more on economic revenue than on journalistic quality and on inciting new ways of journalistic practice (Bagdikian, 2004; McManus, 1994). As pointed out by Mitchelstein and Boczkowski (2009: 564), conservative tendencies such as these are often associated with large owners - a claim that apparently holds true also in the era of online journalism. As traditional media organizations find themselves in an increasingly complex economic climate, large media owners might seek to maximize synergy effects, leading to similar or even identical websites for the newspapers in the organization, rather than providing visitors of the various sites with more diverse material and varied features.

Even though the effect of owner size was found to be non-significant, newspaper size (measured with the circulation variable) proved to be a significant predictor for total interactivity as discussed earlier. Taken together, this indicates that when it comes to employment of interactive features, the characteristics of the individual newspaper itself seem more important than the characteristics of its owner. Perhaps individual newspapers are not that dependent on their respective owners when it comes to decisions regarding website practices.

The fact that the average national newspaper has significantly higher means of total, medium and medium-human interactivity than their local counterparts (as shown in Table 3 ) was addressed earlier. However, the rather low eta ${ }^{2}$-values reported for these differences (ranging from .05 to .08 ) suggest a moderate-at-best effect of national or local affiliation when it comes to the employment of these specific types of interactive features (interpretation guidelines from Cohen, 1988). In other words, even though there are significant differences between national and local newspapers in this regard, these differences are perhaps not as pertinent as might have been expected. While local newspapers tend to employ fewer interactive features than their national counterparts, there appears to be a certain degree of variation at play here.

The effect of competition within region on interactivity was found to be non-significant, a result in line with previous studies on web performance of media organizations engaged in competition (Kiernan and Levy, 1999). As more and more media consumption moves online, competition between online media outlets will inevitably increase. The employment of interactive features could probably come to play an important part in creating attractive websites (as suggested by Chyi and Sylvie, 1998), and as such, this might be an interesting opportunity for the practitioner community.

Breaking down the results for the human-medium category of interactivity, we can conclude that even though 25 per cent of the newspapers in this study allow readers to contribute news of a more 'novelty' character (such as reports from local sporting events, church gatherings or local community events), only 4 per cent of the sites encourage visitors to submit their own full-text news stories. Delving further into the results, we see that even though nearly 40 per cent of the sites feature blogs by non-journalists, only 8 per cent of the sites provide readers with the opportunity to write their own blogs on the newspaper site. Services such as Twingly (twingly.com, n.d.), that allow blog posts on external reader blogs regarding specific articles to appear in association with those articles on the newspaper website, are also being used, although rather moderately (12.3\%). In comparison, nearly 90 per cent of the sites featured a 'news tip-off' function. Taken together, these results imply that while newspapers are eager to obtain news stories and ideas from their readers, they seem hesitant when it comes to letting the readers write those stories themselves. This apparently conservative attitude towards allowing reader contributions might not be a solid strategy in the long run. At a time when blogging and other 'citizen journalism' opportunities are more easily accessible to the general public than ever, allowing users to contribute to the newspaper website might prove to be a better approach, drawing more people to visit as well as revisit the 
specific site. However, while increased opportunities for reader contributions might be an interesting approach in order to involve the readers in the journalistic process, these features also carry with them potential issues of editorial quality control and need for fact checking (Thurman, 2008).

According to the results presented earlier, length of web presence did not emerge as a significant predictor of total interactivity, providing opposing results to the ones presented by earlier studies (Boczkowski, 2004; Chung, 2004; Engebretsen, 2006; Greer and Mensing, 2006; Karlsson, 2006). As rationales for website design come and go quickly (Zeng and $\mathrm{Li}, 2006$ ), a need for flexibility in this regard is probably important in order to keep up with the latest online developments and trends. The results presented here suggest that relative newcomers to the web are able to 'leapfrog' over old and onto new web design paradigms, where focus is placed on employing more interactive features, leaving the pioneers of the medium stuck in old systems difficult to update and harmonize with the latest website design principles.

The two final independent variables included in the analysis focused on the website staff. Whereas the number of web staff did not emerge as a significant predictor of total interactivity (but as a significant one for the medium and medium-human subcategories), the age of staff proved significant in predicting total interactivity. Perhaps younger journalists introduce new ideas and perspectives on website management to the newspaper staff rooms, challenging the work routines of their 'cautious traditionalist' (Chung, 2007: 53) older colleagues. These results might also be explained by the tendency for younger journalists to be more highly educated than their older colleagues (Deuze and Dimoudi, 2002), or, in a more general sense, that younger generations are often described as being better versed in using the web than older people (Facht, 2008). Furthermore, a sizeable web staff is seemingly not enough to create a site rich with a variety of interactive features. Perhaps larger web staffs need to follow stricter guidelines and cannot easily break the norm of established web-working practices within larger media companies with many employees dedicated to the web. While the results presented in this article show that the number of web staff appears to be important, there are also other forces at play when it comes to predicting the degree to which Swedish newspapers provide interactive features on their websites.

As shown in analyses performed in this article, the size variable of circulation and the variable measuring the mean age of web staff emerged as significant predictors of total interactivity. However, for human and human-medium interactive features, only circulation proved to be a significant predictor. For both medium and medium-human interactivity, number of web staff provided significant predictions. The fact that circulation also predicted the medium-human category mirrors the results of Massey (2000), who found that a similar measure correlated positively with the degree of customization features available to site visitors, features grouped under the aforementioned category in this study. Looking at Table 3, we can see that the means for total, medium and medium-human interactivity were significantly higher for national newspaper websites, but not the means for the human and human-medium category. Taken together, these results indicate that while the utilization of features such as chat, discussion forums, reader news tips and so forth (examples of human and human-medium interactive features) depend on the general size and strength of the newspaper (as measured by the circulation variable), websites that feature high levels of medium and medium-human interactive features (such as video streams, interactive news graphics and customizable content) are often associated with national newspapers and require more specific (and perhaps also specially trained) personnel in order to shoot and edit the video to be published on the site, design and implement news graphics features and so on. 
The results from this study provide the research community with insights into why newspapers employ interactive features on their websites to higher or lower degrees. Although the study makes an important contribution to this particular field of research, its limitations need to be clearly addressed. This is done in the next and final section of this article. This section also provides suggestions for future research on the topic at hand.

\section{Limitations and suggestions for future research}

This article has studied different kinds of interactivity available on Swedish newspaper websites, looking specifically at what factors seemingly influence the availability of these features. While approaching this topic with quantitative methods has its merits (and its flaws, for that matter), scholars planning future studies regarding these matters should consider using qualitative methods in order to delve even further into the work rationales of online newsrooms. For example, an ethnographic approach, studying the work routines and rationales of online journalists, might provide the research community with even deeper knowledge of how interactive features such as the ones outlined in this article are thought of and used in the journalistic work environment. Also, from the coefficients reported in Table 3, we can tell that the average Swedish newspaper website offer 35 per cent of human interactivity indicators, 38 per cent of human-medium, 31 per cent of medium and 34 per cent of medium-human interactivity features. Overall, a little more than a third $(35 \%)$ of the features identified in this study are employed by the average newspaper website. With almost two-thirds of interactive features not being used on average, the employment of new ways to interact with site visitors might prove useful for practitioners such as site operators. In relation to this, one might also pose the question of whether 35 per cent is to be considered a high mean percentage of human interactivity, or if 31 per cent should be judged as a low mean for medium interactivity? An interesting idea for future research might be to perform longitudinal studies on online newspapers, collecting data over several years and studying the development of interactive features.

While this study has provided useful results regarding online newspaper use of interactivity, it is nevertheless is a 'snapshot'; of the Swedish media landscape in early 2009. The media industry is indeed a dynamic one, with mergers and takeovers occurring frequently. Such industry actions should be expected to have an effect on a number of influences for the newspapers. Longitudinal studies, as suggested earlier, could also prove to give us insight into the dependent variables used. For example, it might be interesting to see if age of web staff will remain as a significant predictor as today's younger journalists grow older and new generations enter the profession. Also, the role of owner organizations might be subject to change in an ever more competitive media environment. Indeed, Wimmer and Dominick state that 'research is a never-ending process'; (2006: 8), referring to the necessary open-ended nature of perhaps all social science research efforts. These and other questions arise from the results presented here, and could perhaps lead to future research initiatives some of which have been suggested earlier in this article.

Finally, it might be reasonable to ask the question: Does more interactivity always leads to better websites? Even though there seems to be a connection between high levels of interactivity and popularity of websites, the effect of interactivity is frequently described as two-sided. Research suggests that excessive interactivity might hinder user experience, demanding more patience, expertise and cognition of the site visitor, standing in the way of allowing the visitors to understand fully the message provided (Bucy, 2004; Sundar, 2000). In the field of advertising, Liu and Shrum (2009) found that user involvement in the product advertised and internet 
experience were important factors in explaining how user perceptions of interactivity in online advertisements are formed. Similarly, Sohn et al (2007: 116-117) found that 'creating fancy and dynamic websites for attracting consumers may return unexpected negative consequences', suggesting that less than positive effects might be looming unless website operators take time to get to know the preferences of their audiences. Inspired by these results, future research projects focusing on online newspapers should address the question of how much interactivity might be considered 'enough' interactivity in the context of newspaper websites - both from the point of view of the producers of such sites, as well as for the visitors. It might also be interesting to study how different newspaper website visitors perceive different opportunities for interaction. Results from studies such as the ones suggested here should be of use to researchers, as well as to media practitioners interested in providing attractive and suitably interactive websites to their visitors.

\section{References}

Adams JW (2007) U.S. weekly newspapers embrace web sites. Newspaper Research Journal 28(4): 36-50. Aikat DD (1998) News on the Web: Usage trends of an on-line newspaper. Convergence 4(4): 94-110. allebolag.se (n.d.) Available at: http://allabolag.se/ (accessed 21 November 2011).

Arant MD and Anderson JQ (2001) Newspaper online editors support traditional standards. Newspaper Research Journal 22(4): 57.

Bagdikian BH (2004) The New Media Monopoly, Boston, MA: Beacon Press.

Balsvik G (2004) Information Technology Users: Studies of Self-Efficacy and Creativity among Swedish Newspaper Journalists. Stockholm: Economic Research Institute, Stockholm School of Economics.

Beam RA (1993) The impact of group ownership variables on organizational professionalism at daily newspapers. Journalism Quarterly 70(4): 907-918.

Boczkowski PJ (2002) The development and use of online newspapers: What research tells us and what we might want to know. In: Lievrouw L and Livingstone S (eds) The Handbook of New Media: Social Shaping and Consequences of ICTs. London: SAGE, 270-286

Boczkowski PJ (2004) Digitizing the News: Innovation in Online Newspapers, Cambridge, MA: MIT Press.

Bucy EP (2004) Interactivity in society: Locating an elusive concept. The Information Society: An International Journal 20(5): 373-383.

Carlsson U and Facht U (2007) Medie-Sverige: Statistik och analys. 2007. Göteborg: Nordicom-Sverige.

Chan-Olmsted S and Park J (2000) From on-air to online world: Examining the content and structures of broadcast TV stations' web sites. Journalism \& Mass Communication Quarterly 77(2): 321-339.

Chung DS (2004) Into interactivity? How news websites use interactive features. Paper presented at International Communication Association Annual Convention, New Orleans, LA, 27-31 May. Washington, DC: ICA.

Chung DS (2007) Profits and perils: Online news producers' perceptions of interactivity and uses of interactive features. Convergence 13(1): 43-61.

Chung DS (2008) Interactive features of online newspapers: Identifying patterns and predicting use of engaged readers. Journal of Computer-Mediated Communication 13(3): 658-679.

Chung DS and Nah S (2009) The effects of interactive news presentation on perceived user satisfaction of online community newspapers. Journal of Computer-Mediated Communication 14(4): 855-874.

Chyi HI and Sylvie G (1998) Competing with whom? Where? And how? A structural analysis of the electronic newspaper market. Journal of Media Economics 11(2): 1-18.

Cohen J (1988) Statistical Power Analysis for the Behavioral Sciences. Hillsdale, NJ: L. Erlbaum Associates. dagspress.se (n.d.) Swedish Newspaper Publishers' Association. Available at: http://www.dagspress.se/ (accessed 21 November 2011).

Deuze M (2003) The Web and its journalisms: Considering the consequences of different types of newsmedia online. New Media \& Society 5(2): 203-230. 
Deuze M and Dimoudi C (2002) Online journalists in the Netherlands: Towards a profile of a new profession. Journalism 3(1): 85-100.

Dibean W and Garrison B (2001) How six online newspapers use web technologies. Newspaper Research Journal 22(2): 79-94.

Domingo D (2008) Interactivity in the daily routines of online newsrooms: Dealing with an uncomfortable myth. Journal of Computer-Mediated Communication 13(3): 680-704.

Downes EJ and McMillan SJ (2000) Defining interactivity: A qualitative identification of key dimensions. New Media \& Society 2(2): 157-179.

Engebretsen M (2006) Shallow and static or deep and dynamic? Studying the state of online journalism in scandinavia. Nordicom Review 27(1): 3-16.

Facht U (2008) Nordicom-Sveriges Internetbarometer 2007. MedieNotiser. Available at: http://www.nordicom.gu.se/?portal=mr\&main=info_publ2.php\&ex=266 (accessed November 2011).

Frigyes P (2008) Västmakten vill växa vidare. Journalisten (13 November-3 December): 4-6.

Frisk J. (2008) Medier bjuder in engagerade läsare. Journalisten (18-31 March): 14-16.

Gerpott TJ and Wanke H (2004) Interactivity potentials and usage of German press-title web sites: An empirical investigation. Journal of Media Economics 17(4): 241-260.

Gillmor D (2004) We the Media: Grassroots Journalism by the People, for the People. Sebastopol, CA: O'Reilly.

Greer J and Mensing D (2006) Evolution of online newspapers: A longitudinal content analysis, 1997-2003. In: Li X (ed.) Internet Newspapers: The Making of a Mainstream Medium. Mahwah, NJ: Lawrence Erlbaum Associates, 13-32.

Gubman J and Greer J (1997) An analysis of online sites produced by US newspapers: Are the critics right? In: Education in Journalism and Mass Communication Annual Convention, Newspaper Division, Chicago, IL, USA, 30 July-2 August 1997.

Hadenius S and Weibull L (1999) The Swedish newspaper system in the late 1990s. Tradition and transition. Nordicom Review 20(1): 129-152.

Holsti OR (1969) Content Analysis for the Social Sciences and Humanities. Reading, MA: Addison-Wesley.

Hujanen J and Pietikainen S (2004) Interactive uses of journalism: Crossing between technological potential and young people's news-using practices. New Media \& Society 6(3): 383-401.

Jensen JF (1998) Interactivity: Tracking a new concept in media and communication studies. Nordicom Review 19(1): 19.

Karlsson M (2006) Nätjournalistik: en explorativ fallstudie av digitala mediers karaktärsdrag pa fyra svenska nyhetssajter, Lund: Avdelningen för medie- och kommunikationsvetenskap, Lunds universitet.

Kiernan V and Levy MR (1999) Competition among broadcast-related web sites. Journal of Broadcasting \& Electronic Media 43(2): 271-279.

Kiousis S (2002) Interactivity: A concept explication. New Media \& Society 4(3): 355-383.

Koehler W (2002) Web page change and persistence - A four-year longitudinal study. Journal of the American Society for Information Science and Technology 53(2): 162-171.

Koolstra CM and Bos MJW (2009) The development of an instrument to determine different levels of interactivity. International Communication Gazette 71(5): 373-391.

Krippendorff K (2004) Content Analysis: An Introduction to Its Methodology, Thousand Oaks, CA: SAGE.

Lacy S (1989) A model of demand for news: Impact of competition on newspaper content. Journalism Quarterly 66(1): 41-48, 128.

Lin CA and Jeffres LW (2001) Comparing distinctions and similarities across websites of newspapers, radio stations, and television stations. Journalism \& Mass Communication Quarterly 78(3): 555-573.

Liu YP and Shrum LJ (2009) A dual-process model of interactivity effects. Journal of Advertising 38(2): 53-68.

Martin SE and Hansen KA (1998) Newspapers of Record in a Digital Age: From Hot Type to Hot Link, Westport, CT: Praeger. 
Massey BL (2000) Market-based predictors of interactivity at Southeast Asian online newspapers. Internet Research-Electronic Networking Applications and Policy 10(3): 227-237.

McManus JH (1994) Market-Driven Journalism: Let the Citizen Beware? Thousand Oaks, CA: SAGE.

McMillan SJ (2000a) Interactivity is in the eye of the beholder: Function, perception, involvement, and attitude toward the website. In: Proceedings of the 2000 Conference of the American Academy of Advertising (ed. MA Shaver), East Lansing, MI: Michigan State University, pp. 71-78. Richmond, VA: American Academy of Advertising.

McMillan SJ (2000b) The microscope and the moving target: The challenge of applying content analysis to the World Wide Web. Journalism \& Mass Communication Quarterly 77(1): 80-98.

McMillan SJ (2002a) Exploring models of interactivity from multiple research traditions: Users, documents, and systems. In: Lievrouw L and Livingstone S (eds) The Handbook of New Media: Social Shaping and Consequences of ICTs. Thousand Oaks, CA: SAGE, 163-182.

McMillan SJ (2002b) A four-part model of cyber-interactivity: Some cyber-places are more interactive than others. New Media \& Society 4(2): 271-291.

McMillan SJ and Hwang JS (2002) Measures of perceived interactivity: An exploration of the role of direction of communication, user control, and time in shaping perceptions of interactivity. Journal of Advertising 31(3): 29-42.

McMillan SJ, Hwang JS and Lee G (2003) Effects of structural and perceptual factors on attitudes toward the website. Journal of Advertising Research 43(4): 400-409.

Mitchelstein E and Boczkowski PJ (2009) Between tradition and change: A review of recent research on online news production. Journalism 10(5): 562-586.

Nerone J and Barnhurst KG (2001) Beyond modernism: Digital design, Americanization and the future of newspaper form. New Media \& Society 3(4): 467-482.

Newhagen JE and Cordes JW (1995) Nightly@nbc.com: Audience scope and the perception of interactivity in viewer mail on the Internet. Journal of Communication 45(3): 164.

Outing S (2001) News Sites Repeat the Mistakes of the Past: We Still Don't Recognize the Power of Interactivity. Available at: http://www.editorandpublisher.com/editorandpublisher/features_columns/article_display.jsp?vnu_content_id=1461161 (accessed 13 october 2009).

Pavlik J (2000) The impact of technology on journalism. Journalism Studies 1(2): 229-237.

Peng FY, Tham NI and Xiaoming H (1999) Trends in online newspapers: A look at the US web. Newspaper Research Journal 20(2): 52-63.

Picard RG (1989) Media Economics: Concepts and Issues. Newbury Park, CA: SAGE.

Quinn G and Trench B (2002) Online news media and their audiences: Multimedia content in the digital age. MUDIA. Heerlen, the Netherlands: IST.

Rafaeli S and Sudweeks F (1997) Networked interactivity. Journal of Computer-Mediated Communication 2(4): $1-6$.

Riley PK, Colleen M, Christiansen T, et al. (1998) Community or colony: The case of online newspapers and the web. Journal of Computer-Mediated Communication 4(1): 1-14.

Schultz T (1999) Interactive options in online journalism: A content analysis of 100 U.S. newspapers. Journal of Computer-Mediated Communication 5(1): 1-24.

Schultz T (2000) Mass media and the concept of interactivity: An exploratory study of online forums and reader email. Media, Culture \& Society 22(2): 205-221.

Shyam Sundar S (2000) The Internet - multimedia effects on processing and perception of online news: A study of picture, audio, and video downloads. Journalism Quarterly 77(5): 480-499.

Sohn DY and Lee BK (2005) Dimensions of interactivity: Differential effects of social and psychological factors. Journal of Computer-Mediated Communication 10(3): 1-16.

Sohn DY, Ci C and Lee BK (2007) The moderating effects of expectation on the patterns of the interactivityattitude relationship. Journal of Advertising 36(3): 109-119.

Song JH and Zinkhan GM (2008) Determinants of perceived web site interactivity. Journal of Marketing 72(2): 99-113. 
Sundar SS (2004) Theorizing interactivity's effects. The Information Society: An International Journal 20(5): $385-389$.

Sundar SS (2000) Multimedia effects on processing and perception of online news: A study of picture, audio, and video downloads. Journalism \& Mass Communication Quarterly 77(3): 480-499.

Tankard J and Ban H (1998) Online newspapers: Living up to their potential? In: Annual Convention of the Association for Journalism and Mass Communication, Baltimore, MD, USA, 5-8 August 1998.

Thurman N (2008) Forums for citizen journalists? Adoption of user generated content initiatives by online news media. New Media \& Society 10(1): 139-157.

Thurman N and Myllylahti M (2009) Taking the paper out of news. Journalism Studies 10(5): 691-708.

twingly.com (n.d.) Available at: http://www.twingly.com/ (accessed 21 November 2011).

Walther JB and Burgoon JK (1992) Relational communication in computer-mediated interaction. Human Communication Research 19(1): 50-88.

Weare C and Lin WY (2000) Content analysis of the World Wide Web: Opportunities and challenges. Social Science Computer Review 18(3): 272-292.

Wimmer R and Dominick J (2006) Mass Media Research: An Introduction. Belmont, CA and London: Thomson Wadsworth.

Wu G (1999) Perceived interactivity and attitude toward websites. In: Proceedings of the 1999 Conference of the American Academy of Advertising (ed. MS Roberts). Gainesville: University of Florida, USA, March 1999, pp. 254-262. Richmond, VA: American Academy of Advertising.

Zeng Q and Li X (2006) Factors influencing interactivity of Internet newspapers: A content analysis of $106 \mathrm{U}$. S. newspapers' web sites. In: Li X (ed.) Internet Newspapers: The Making of a Mainstream Medium. Mahwah, NJ: Lawrence Erlbaum Associates, 139-158.

\section{Biography}

Anders Olof Larsson is a PhD candidate at the Department of Informatics and Media, Uppsala University, Sweden. He is also associated with The Swedish Research School of Management and Information Technology. Larsson's research has been published in journals such as First Monday and New Media and Society. His research interests include institutional and audience use of online interactivity and social media. Anders Olof Larsson's website can be found at http://www.andersoloflarsson.se. 